\title{
ОЦЕНКА ТЕХНИЧЕСКОЙ ЭФФЕКТИВНОСТИ КОМПАНИЙ ОБОРОННО-ПРОМЫШЛЕННОГО КОМПЛЕКСА ${ }^{1}$
}

\author{
Е.А. Федорова ${ }^{2}$, А.А. Ткаченко \\ Ф.Ю. Федоров ${ }^{4}$ Е.С. Мазалов
}

В данном исследовании оценивается операционная (по рентабельности) и техническая эффективность предприятий оборонно-промышленного комплекса. Эмпирическая база включает финансовые и экономические показатели 1425 предприятий ОПК, метод исследования - непараметрический метод DEA (Data Envelopment analysis). Ha основе проведенного анализа было выявлено следующее:

1. Нельзя оценивать эффективность работы компании ОПК, основываясь только на технической эффективности. Предприятие может иметь невысокую рентабельность, но при этом, в силу производственной специфики, работать более эффективно.

2. Предприятия ОПК с высокой долей госучастия (85-100\%) работают более эффективно, в связи с модернизацией основных производственных фондов и увеличением контрактной базы за счет государственных программ.

3. Предприятия, имеющие контрактную базу свыше 500 млн руб., имеют более высокую рентабельность $(5,1 \%)$, чем предприятия с контрактной базой менее 500 млн руб. (-104\%).

4. Санкции, введенные странами запада в отношении российских предприятий ОПК, не смогли в значительной мере повлиять на техническую эффективность предприятий в 2014 году.

Ключевые слова: предприятия ОПК, техническая эффективность, операционная эффективность, санкции.

JEL:

Оборонно-промышленный комплекс всегда занимал особое место в народнохозяйственной системе страны, оказывая прямое влияние на национальную безопасность государства, а также на экономическое развитие, внешнеполитическую ситуацию и темпы научнотехнического прогресса. Политика государства выступает главным фактором, оказывающим воздействие на развитие оборонной промышленности России в условиях мирного времени. Однако вопросы, связанные с оценкой эффективности компаний оборонно-промышленного комплекса, также являются актуальными. В связи с тем что стандартные показатели операционной эффективности (показатели прибыли и рентабельности) могут не учитывать ориентацию предприятий на внешние контракты и заинтересованность государства, стоит рассмотреть показатель технической эффективности.

Предприятия ОПК - совокупность научно-исследовательских, испытательных организаций и производственных предприятий, выполняющих разработку, производство, хранение, постановку на вооружение военной и специальной техники, боеприпасов для государственных силовых структур, а также на внешние рынки. В отрасли сосредоточена большая часть передовых технологий военного и гражданского назначения. Критические направления развития технологической базы ОПК не только совпадают, но и зачастую формируют ключевые направления научно-технологического прогресса в целом. В настоящее время порядка 45\% продукции военного назначения предназначены для внутренних потребностей заказчика в лице Министерства обороны Российской Федерации, 22\% - для внешнего рынка по линии военно-технического сотрудничества (ВТC), 33\% - гражданская продукция общего пользования (одежда, транспорт, связь, телекоммуникации и т.д.)

Для оценки эффективности компаний ОПК были сформулированы следующие гипотезы.

1. Статья подготовлена по результатам исследований, выполненных по гранту РГНФ, №15-02-00622

2. Доктор экономических наук, профессор, кафедра финансового менеджмента, Финансовый университет при Правительстве РФ.

3. Кафедра финансового менеджмента, Финансовый университет при Правительстве РФ.

4. Аспирант, кафедра прикладной математики, Финансовый университет при Правительстве РФ.

5. Кафедра корпоративных финансов, Финансовый университет при Правительстве РФ. 
Гипотеза 1: предприятия ОПК с государственным участием работают более эффективно, чем предприятия с частной собственностью.

Наша гипотеза основана на том, что предприятия с высокой долей госучастия получают значительную поддержку из федерального бюджета на модернизацию основных фондов и пополнение контрактной базы. В 2011 г. была принята Государственная программа вооружения до 2020 г. (ГПВ-2020) ${ }^{1}$, которая обеспечит портфель заказов отечественным предприятиям в размере 20 трлн рублей. Данная программа позволит оснастить российскую армию современными средствами военной техники и вооружения. Важно также отметить Федеральную целевую программу развития оборонно-промышленного комплекса на 2011 2020 годы (ФЦП-2020)른 в соответствии с которой предприятия получат до 3 трлн рублей на модернизацию и техническое перевооружение производства.

Гипотеза 2: Внешние экспортные контракты позволяют предприятиям ОПК работать более эффективно.

Другими словами, чем выше сумма контрактов, тем более высокую прибыль получают предприятия и больше инвестиций могут направлять на модернизацию основных производственных фондов и разработку НИОКР.

На мировом рынке США и Россия остаются крупнейшими в мире экспортерами основных видов обычных вооружений на протяжении последних пяти лет ${ }^{3}$. Согласно рейтингу, опубликованному SIPRI, пятерку крупнейших поставщиков вооружения по-прежнему возглавляют США, на долю которых приходится 31\% глобального экспорта оружия. Остальными крупнейшими экспортерами в этой области в мире являются Россия, Китай, Германия и Франция. Их совместная доля в мировой торговле оружием составила $74 \%$, в то время как доля только России и США - 58\%.

Объем экспорта оружия в России за последние годы превысил 10 млрд долл. В 2014 г. он составил 15,5 млрд долл. Основные поставки приходятся на страны Восточный Европы, Латинской Америки, Индии, Алжира и Китая. Распределение объема продукции военного назначения в 2014 г. было следующим: по технике ВВС - 41\%, ВМФ - 13\%, ПВО - 15\%, сухопутных войск - 27\% ${ }^{4}$, на иную продукцию около 4\%. Подавляющая часть российского экспорта осуществляется через государственную компанию «Рособоронэкспорт» (единственный в России государственный посредник по экспорту/импорту всего спектра конечной продукции, технологий и услуг военного и двойного назначения).

Гипотеза 3: Санкции повлияли на эффективность работы оборонной промышленности. Оборонная промышленность стала менее эффективна из-за ограничений в вывозе и частичной или полной заморозки платежей со стороны стран, установивших санкции.

На предприятия ОПК в первую очередь повлияли санкции, введенные практически всеми странами ЕС. Вследствие этогобыла введена блокировка платежей черезстраны, установившие барьеры, а также запрещен экспорт и импорт оружия, экспорт товаров двойного назначения и высоких технологий, которые могут быть использованы в оборонной промышленности. Например: Германия приостановила выполнение военного контракта с Россией стоимостью 120 млн евро.

В 2014 г. американские власти ввели санкции в отношении ряда российских оборонных предприятий, таких как «Алмаз-Антей», «Уралвагонзавод», НПО машиностроения и несколько структур «Ростеха»: концерны «Калашников» (бывший «Ижмаш»), 1. Указ Президента Российской Федерации от 07.05.2012 № 603 . О реализации планов (программ) строительства и развития Вооруженных Сил Российской Федерации, других войск, воинских формирований и органов и модернизации оборонно-промышленного комплекса.

2. Минпромторг . URL: old.minpromtorg.gov.ru>ministry/fcp/6.

3. Информационное агентство Оружие России. URL: http://www.arms-expo.ru/news/vzaimodeystvie/ssha_i rossiya_ostayutsya_krupneyshimi_v_mire_eksporterami_oruzhiya_sipri/

4. Информационное агентство Оружие Росси. URL: http://www.arms-expo.ru/news/vzaimodeystvie/ssha_i rossiya_ostayutsya_krupneyshimi_v_mire_eksporterami_oruzhiya_sipri/

5. Рособоронэкспорт. URL: http://www.roe.ru/roe/rus_status.html 
«Созвездие», «Радиоэлектронные технологии» (КРЭТ), «Базальт» и Конструкторское бюро приборостроения. Российский оборонный концерн «Алмаз-Антей» также был внесен в санкционный список Евросоюза .

США блокировали доступные американской юрисдикции активы пяти российских оборонных компаний: «Алмаз-Антей» (один из крупнейших мировых производителей систем ПВО), Научно-исследовательский институт приборостроения (производитель систем для боевых самолетов и систем ПВО), Мытищинский машиностроительный завод, Машиностроительный завод имени Калинина, а также «Исследовательско-производственный центр в Долгопрудном» ${ }^{1}$.

В новый, расширенный санкционный список Канады в отношении России попал Сбербанк и пять оборонных предприятий Российской Федерации: «Исследовательскопроизводственный центр в Долгопрудном», ОАО «Машиностроительный завод имени М.И. Калинина» (МЗиК), ОАО «Мытищинский машиностроительный завод», ОАО «Научноисследовательский институт приборостроения имени В.В. Тихомирова» (НИИП) 2 и т.Д..

\section{Методология исследования}

Bсе предложенные гипотезы будут проверены одним из способов анализа технической эффективности - непараметрическим методом DEA (Data Envelopment analysis). Метод «оболочечного анализа» позволяет определить наиболее эффективные предприятия путем оценивания группы действующих единиц и сравнения их технической эффективности. Если при заданном количестве ресурсов невозможно произвести больше выпусков, производство технически эффективно. Эффективность рассчитывается как соотношение суммы взвешенных результатов деятельности компании к сумме взвешенных средств.

За последние несколько лет метод DEA получил широкое распространение по всему миру. Во многих экономических статьях зарубежных авторов рассматриваются различные способы применения DEA для оценки эффективности функционирования однородных объектов в различных отраслях экономики. Так, исследование Сатоши Осато и Масако Тахакаши [Ohsato and Takahashi, 2015] из университета Кэйо посвящено оценке эффективности японских региональных банков и их отделов с помощью аддитивной модели типа Slacks Based Measure c переменным эффектом от масштаба, позволяющей одновременно минимизировать входы и максимизировать выходы. Сара Брей, Леонардо Каджиани и Мишель Оттоманелли ([Bray, Caggiani, and Ottomanelli, 2015)] рассматривают возможность оценки эффективности транспортных систем в условиях неопределенности с помощью теории нечётких множеств на основе метода оболочечного анализа данных. Также в их статье приведено сравнение оценок эффективности международных контейнерных портов полученных с помощью нечеткой модели DEA и ее традиционной версией. В работе Софин Гали и Сами Резгай [Ghali and Rezgui, 2011) на основе данных 674 фирм за период 1997-2001 гг. исследуется вклад ПИИ в техническую эффективность фирм.

Стоит отметить, что метод DEA также успешно применяется и в России. Например, Т.И. Овчинниковапроводила исследование конкурентоспособности предприятий молочной промышленности Воронежской области на основании метода DEA. В ходе исследования ставится задача минимизации расходов за счет нематериальных активов, при сохранении объемов выпуска продукции.

В работе А.И. Ампилогова [Ампилогов, 2011] рассматривается оценка рисков банкротства российских фирм с помощью метода оболочечного анализа на примере компаний производящих оборудование для нефтехимической отрасли. Оценка проводилась по данным 73 компаний за период с 2007 по 2009 г. с помощью моделей CCR и BCC по двум группам переменных. Первая группа - классический набор переменных из статьи Альтмана, во второй группе на вход были отобраны выручка от реализации продукции и услуг и основные

1. РИА Новости. URL: http://ria.ru/spravka/20150216/1046144422.html\#ixzz3hem1Kcsp.

2. РИА Новости. URL: http://ria.ru/spravka/20150216/1046144422.html\#ixzz3hem1Kcsp. 
средства, а на выход - кредиторская задолженность, краткосрочные займы и кредиты и разница между кредиторской задолженностью и выручкой.

Исследование по применению DEA-методологии для оценки эффективности компаний с ПИИ по отраслям и отечественных компаний проводили в своей статье Е.А. Федорова, Б.К. Коркмазова и М.А. Муратов [Федорова, Коркмазова, Муратов, 2015]. Анализ основан на сравнении показателей рентабельности и индекса эффективности по данным 23567 предприятий с долей иностранного капитала и 14653 организаций без него за период с 2008 по 2012 г. Все гипотезы проверяются с помощью модели, ориентированной на выход BCC-output. Техническая эффективность сначала измеряется с использованием классических показателей (на вход: численность сотрудников, активы, основные средства), а затем были использованы показатели спилловерэффектов на вход и на выход выручки.

В рамках данной работы метод DEA будет применен к оценке эффективности организаций оборонной промышленности. Оценка проводилась по восьми различным модификациям модели (с переменным VRSIN/VRSOUT и постоянным эффектом от масштаба CRSIN/ CRSOUT, с убывающим DRSIN/DRSOUT и возрастающим IRSIN/IRSOUT эффектом от масштаба) отличающихся набором предположений и ориентацией на вход или выход. Рассмотренные модификаций интересны прежде всего систематическими различиями между результатами сравнительного тестирования. Стоит отметить, что в больших моделях показатели эффективности фирмы меньше, а оценка потенциала улучшения компании более оптимистична.

Теперь одним из самых важных вопросов для обсуждения является вопрос о выборе модели, от него зависит уровень дохода компании. На практике при выборе среди VRS-, DRS-, IRS- и CRS-моделей фирмы обычно предпочитают модель VRS, выдающую более высокие показатели эффективности, например, более высокую норму стоимости. В то время как CRS является худшей альтернативой для большинства фирм, а выбор между DRS и IRS делают с переменным успехом.

Для дальнейшего анализа эффективности организаций ОПК мы остановились на выборе одной из самых распространенных моделей - DEA-модели, BCC-output (или VRS) c переменным эффектом от масштаба, предложенной в 1984 г. Банкером, Чарнсом и Купером. При использовании переменной отдачи от масштаба большее количество предприятий могут быть обозначены как эффективные. Такой результат достигается за счет того, что изменение входных параметров могут привести к непропорциональному изменению параметров выхода. К достоинствам данной модели также можно отнести возможность обрабатывать отрицательные величины.

Таким образом, модель ВСС является одной из наиболее реалистичных. В связи с этим для последующего анализа будет использована оценка технической эффективности компаний ОПК, полученная с помощью модели ВCC-output, ориентированной на выход, с переменным эффектом от масштаба. Данная модель позволяет максимизировать выпуски при заданном уровне ресурсов. Формальный вид модели:

$$
\mathrm{e}_{0}=\frac{\sum_{\mathrm{j}=1}^{\mathrm{s}} \mathrm{u}_{\mathrm{j}} \mathrm{y}_{\mathrm{j} 0}+\mathrm{u}_{0}}{\sum_{\mathrm{i}=1}^{\mathrm{r}} \mathrm{v}_{\mathrm{i}} \mathrm{x}_{\mathrm{i} 0}} \rightarrow \max \text { ! }
$$

при условии:

$$
\frac{\sum_{\mathrm{j}=1}^{\mathrm{s}} \mathrm{u}_{\mathrm{j}} \mathrm{y}_{\mathrm{jm}}+\mathrm{u}_{0}}{\sum_{\mathrm{i}=1}^{\mathrm{r}} \mathrm{v}_{\mathrm{i}} \mathrm{x}_{\mathrm{im}}} \leq 1
$$

где $\mathrm{u} 0$ - эффект масштаба, $\mathrm{u} 0<0, \mathrm{u} 0>0, \mathrm{u} 0=0$, при этом:

$\mathrm{u} 0<0$ - то это убывающая отдача масштаба;

u0 > 0 - то это возрастающая отдача масштаба; 
$\mathrm{u} 0<0$ - то это постоянная отдача масштаба.

В качестве параметров (рис. 1) будем использовать классический набор показателей: на вход число сотрудников, чистую прибыль/убыток, действующую контрактную базу, задолженность перед банками, денежные средства; на выход - выручку. Таким образом будет происходить максимизация выручки при заданном уровне входящих параметров.
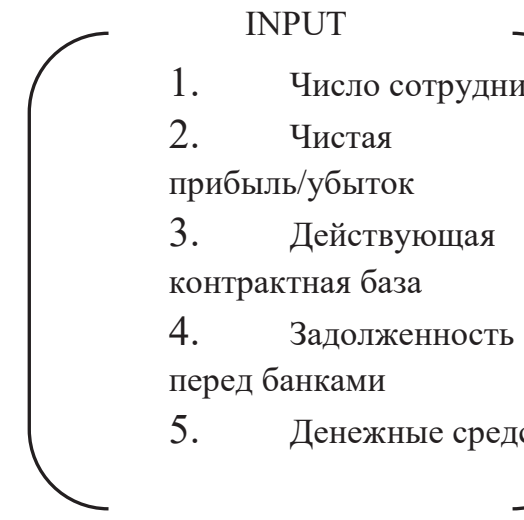

4. Задолженность перед банками

5. Денежные средства

Модель: ВСС ОUTPUT
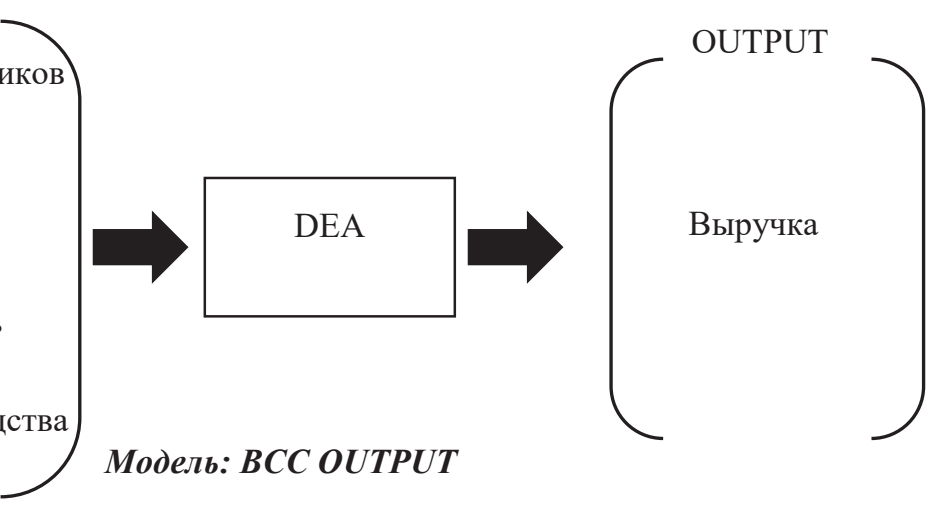

Рисунок1. Входы и выходы модели

\section{Анализ данных}

Согласно приказу Министерства промышленности и торговли Российской Федерации от 22 апреля 2014 г. № 758 «Об утверждении перечня организаций, включённых в сводный реестр организаций оборонно-промышленного комплекса» ${ }^{1}$ и в соответствии с постановлением Правительства Российской Федерации от 20 февраля 2004 г. № 96 «О сводном реестре организаций оборонно-промышленного комплекса»², в реестр включены 1339 предприятий. В отрасли сконцентрированы высококвалифицированные кадры отечественной научнопромышленной сферы, общая численность работников составляет около 3 млн человек. В настоящее время количество предприятий оборонной промышленности превышает 1400 организаций. В нашей работе был проведен анализ по 1425 компаниям.

Ниже в таблице 1 представлена статистика input и output переменных используемых в модели.

Прирост основных показателей за 2013-2014 гг., \%

\begin{tabular}{|c|c|c|c|c|c|c|}
\hline & $\begin{array}{c}\text { Выручка, } \\
\text { тыс. руб. }\end{array}$ & $\begin{array}{c}\text { Прибыль/ } \\
\text { убок, тыс. } \\
\text { руб. }\end{array}$ & $\begin{array}{c}\text { Задолж. перед } \\
\text { Банками, } \\
\text { тыс. руб. }\end{array}$ & $\begin{array}{c}\text { Ден. ср-ва и } \\
\text { кратк. фин. } \\
\text { вложения, тыс. } \\
\text { руб. }\end{array}$ & $\begin{array}{c}\text { Числ. работни- } \\
\text { ков, чел. }\end{array}$ & $\begin{array}{c}\text { Действующая } \\
\text { контрактная база, тыс. } \\
\text { руб. }\end{array}$ \\
\hline 1 квартиль & 7,01 & 13,16 & 0 & 2,82 & 1,60 & 30,02 \\
\hline Медиана & 8,88 & 10,84 & 1 & 2,87 & 0,94 & 30,00 \\
\hline Среднее & 12,94 & 20,71 & 1 & 2,74 & 1,13 & 29,79 \\
\hline 3 квартиль & 11,36 & 15,06 & 1 & 2,71 & 4,89 & 30,00 \\
\hline
\end{tabular}

Стоит отметить, что, несмотря на нестабильную политическую ситуацию, значение всех основных балансовых показателей в 2014 г. увеличилось. Среднее значение выручки возросло на 12,9\%, а среднее значение прибыли - на 20,7\%. Действующая контрактная база значительно увеличилась, ее прирост составил 29,8\%. Основываясь на результатах представленной статистики, можем предположить, что санкции практически не оказали существенного влияния на операционную деятельность, несмотря на частичную или полную

1. Минпромторг. URL: http://minpromtorg.gov.ru/docs/\#!1938

2. Минпромторг. URL: http://minpromtorg.gov.ru/docs/\#!1938 
заморозку платежей.

Результаты исследования

Указанные выше переменные были использованы для построения модели с переменным эффектом от масштаба BCC-output. Граница эффективности полученной модели приведена на рисунке 2. Эффективные компании лежат на самой кривой эффективности, неэффективные - ниже.

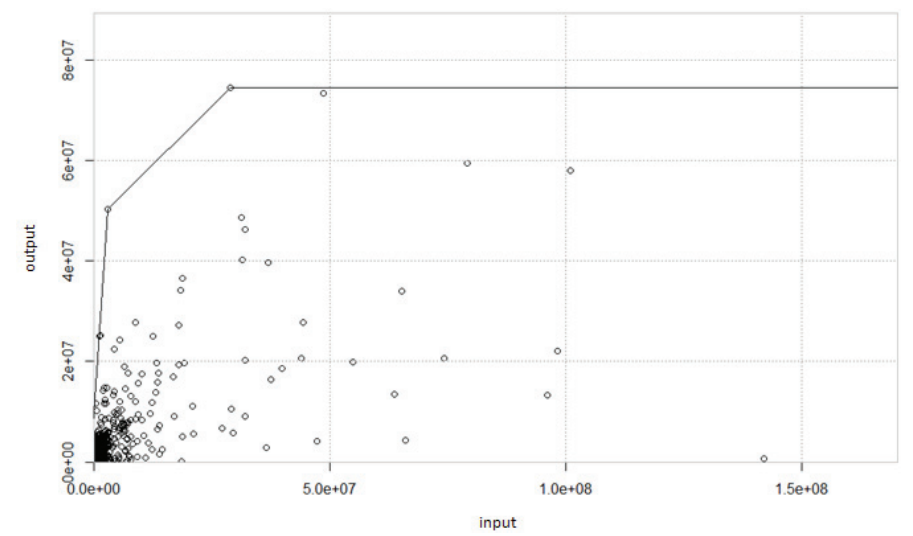

Рисунок 2. Графическая интерпретация оценки эффективности в модели BCC-output

Сводные результаты по расчету технической эффективности за 2013-2014 гг. представлены в таблице 2.

Таблица 2

Средняя инновационная эффективность предприятий оборонной промышленности

\begin{tabular}{|c|c|c|c|c|c|c|c|c|}
\hline Год & $\begin{array}{c}\text { Число } \\
\text { организ. }\end{array}$ & $\begin{array}{c}\text { Число } \\
\text { эффект, } \\
\text { организ. }\end{array}$ & $\begin{array}{c}\text { Средняя } \\
\text { эффект, (M) }\end{array}$ & $\begin{array}{c}\text { Стандартное } \\
\text { отклонение (s) }\end{array}$ & \multicolumn{3}{|c|}{$\begin{array}{c}\text { Интервал } \\
\text { \% организ. } \\
\text { в I }\end{array}$} & $\begin{array}{c}\text { \% орган, с техн. } \\
\text { эффект, ниже } \\
\text { среднего }\end{array}$ \\
\hline 2013 & 1425 & 81 & 0,440 & 0,2415 & 0,198 & 0,681 & $69,5 \%$ & $56,6 \%$ \\
\hline 2014 & 1425 & 81 & 0,418 & 0,2350 & 0,183 & 0,653 & $71,8 \%$ & $56,4 \%$ \\
\hline
\end{tabular}

Средняя оценка технической эффективности (М) представляет собой среднее значение всех оптимальных значений, полученных от ВСС-модели для каждого предприятия оборонного сектора. За период с 2013 по 2014 г. ее значение незначительно снизилось, в то время как общее количество эффективных организаций не изменилось. Процент компаний в пределах интервала стандартного отклонения от средней эффективности увеличился на 2,3\%. Для более детального анализа рассмотрим гистограмму распределения эффективностей (рис. 3).

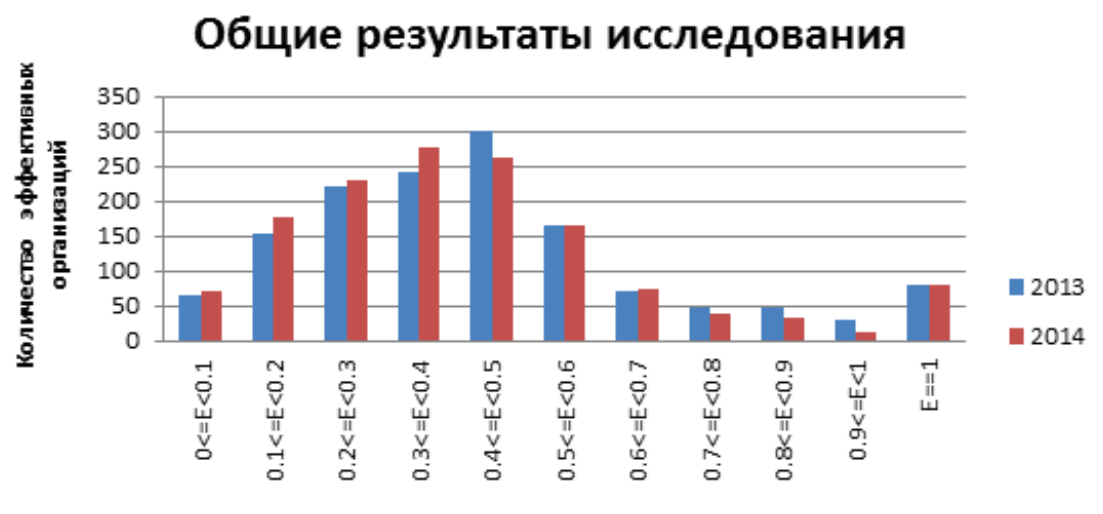

Интервалы эффективности

Рисунок 3. Гистограмма распределения эффективностей по модели ВCC-output

По гистограмме видно, что в 2014 г. количество компаний с эффективностью от 70-99\% снизилось, в то время как с эффективностью 30-39\% увеличилось. На основании этого можно 
сделать вывод о том, что по сравнению с 2013 г. компании с высокой эффективностью снизили свои показатели.

Перейдем к рассмотрению результатов по расчетам эффективности в соответствии с предложенными нами гипотезами (табл. 3).

Таблица 3

Результаты расчетов по гипотезам

(анализ проводился по 1425 компаниям оборонного сектора России) ${ }^{1}$

\begin{tabular}{|c|c|c|c|c|c|c|c|}
\hline \multirow{2}{*}{ Год } & \multirow{2}{*}{ Показатели } & \multicolumn{4}{|c|}{ Доля государства } & \multicolumn{2}{|c|}{$\begin{array}{c}\text { Действующая } \\
\text { контрактная } \\
\text { база участников } \\
\text { ВЭД }\end{array}$} \\
\hline & & $0 \%$ & $\begin{array}{c}85- \\
100 \%\end{array}$ & нет & да & $\begin{array}{c}\text { до } 500 \\
\text { млн } \\
\text { руб. }\end{array}$ & $\begin{array}{c}\text { свыше } \\
500 \\
\text { млн } \\
\text { руб. }\end{array}$ \\
\hline \multirow{4}{*}{2013} & Кол-во эфф. & 14 & 67 & 70 & 11 & 4 & 7 \\
\hline & $\begin{array}{c}\text { Средняя } \\
\text { рентабельность } \\
\text { продаж }\end{array}$ & 5,056 & 0,021 & 2,262 & $-0,073$ & $-1,044$ & 0,051 \\
\hline & Cp. DEA & 0,4125 & 0,4528 & 0,4529 & 0,4004 & 0,3972 & 0,4046 \\
\hline & $\begin{array}{c}\text { Количество } \\
\text { компаний }\end{array}$ & 467 & 958 & 1064 & 361 & 205 & 156 \\
\hline \multirow{4}{*}{2014} & Кол-во эфф. & 12 & 69 & 70 & 11 & 4 & 7 \\
\hline & $\begin{array}{c}\text { Средняя } \\
\text { рентабельность } \\
\text { продаж }\end{array}$ & 5,305 & 0,175 & 2,510 & $-0,069$ & $-0,974$ & 0,025 \\
\hline & Cp. DEA & 0,3828 & 0,4346 & 0,4304 & 0,3801 & 0,3735 & 0,3868 \\
\hline & $\begin{array}{c}\text { Количество } \\
\text { компаний }\end{array}$ & 467 & 958 & 1064 & 361 & 181 & 180 \\
\hline
\end{tabular}

Из них 956 компаний имеют долю государства свыше 85\% и только две - 47\% и 56\%, поэтому мы разбили выборку на предприятия без государственного участия и с 85-100\% государственной собственности. 100\% государственной собственности имеют такие холдинги, как: «Уралвагонзавод», «Ростехнологии», «Объединенная авиастроительная корпорация», «Концерн ПВО «Алмаз-Антей», «Федеральное космическое агентство», «Корпорация тактическое ракетное вооружение», «Объединенная судостроительная корпорация» и т.д.

Первая гипотеза подтвердилась. Если мы рассмотрим операционную эффективность, то рентабельность предприятий ОПК с высокой долей государственной собственности в капитале очень низка, всего 2\%. При этом, если мы посмотрим на техническую эффективность, то количество эффективных компаний с высокой долей государственной собственности намного больше, чем для компаний с частной собственностью. В 2013 г. количество эффективных предприятий с долей государства было 67, что в 4,8 раза выше, чем для предприятий без государственного участия. Аналогичная ситуация наблюдается и в 2014 г., разница становится более очевидной.

Что касается второй гипотезы, то она подтвердилась лишь частично.

Предприятия, имеющие контракты ВЭД, не являются более эффективными, так как по результатам расчетов их показатели намного хуже. Среди них количество эффективных организаций в 7 раз ниже, чем у предприятий, работающих внутри страны и имеющих значительный объем контрактов, финансируемых из государственного бюджета. Однако у предприятий, которые получили экспортные контракты на сумму свыше 500 млн руб., более высокая рентабельность и техническая эффективность. Стоит отметить, что в 2014 г. на 15\% увеличилось количество предприятий с действующей контрактной базой свыше 500 млн. руб.

1. Вся информация бралась из открытых источников информации. URL: www.spark-interfax.ru, www.sipri.org., www.roe.ru, www.rulsna.com, minpromtorg.gov.ru, ria.ru) 
Современные рыночные условия диктуют тенденции для развития экспортных направлений в сегменте ОПК (высокоточное наступательное вооружение, стрелковое вооружение, двигатели для космических аппаратов, авиационная отрасль и т.д.). Большинство предприятий на текущий момент работают для потребностей внутреннего рынка и гражданской продукции, занимая ниши смежных отраслей и работая над выполнением государственных программ ГПВ и ФЦП.

Предложенная нами третья гипотеза подтвердилась. Из гистограммы на рисунке 3 можно сделать вывод о том, что многие предприятия в 2014 г. снизили свою эффективность. По таблице 3 видно, что средняя техническая эффективность снизилась всего на 4-7\% как среди предприятий с долей государства и без, так и среди организаций, ведущих внешнеэкономическую деятельность. Таким образом, санкции, введенные ЕС, лишь незначительно повлияли на работу организаций ОПК, в связи с тем что основными нашими рынками сбыта по-прежнему остаются Китай, Ирак, Индия и Вьетнам и Алжир. В потенциале - выход на рынки Бахрейна, Намибии, Нигерии, Джибути, Танзании, Кении, Эфиопии, Саудовской Аравии, Катара и Бразилии ${ }^{1}$. Российская Федерация хорошо зарекомендовала себя на рынке и остаётся надежным партнёром в поставках, современного, конкурентоспособного вооружения, не уступая аналогичной продукции США, о чем свидетельствует увеличивающийся из года в год объем экспорта.

Таким образом, на основе нашего исследования можно сделать следующие выводы:

1. Нельзя оценивать эффективность работы предприятий ОПК, основываясь только на операционной эффективности. Предприятие может иметь низкую рентабельность, но при этом благодаря высокой доле государственного участия работать эффективно.

2. Предприятия ОПК с долей государственной собственности 85-100\% работают более эффективно, что обусловлено модернизацией основных производственных фондов и увеличением контрактной базы за счет государственных программ.

3. Компании, которые являются участниками ВЭД, работают менее эффективно, чем компании, которые не экспортируют вооружение. Среди них организации, которые имеют внешние контракты выше 500 млн руб., имеют более высокую рентабельность $(5,1 \%)$, чем ОПК с контрактами ниже 500 млн руб. (-104\%).

4. Что касается санкций, которые ввели страны Запада в отношении российских предприятий ОПК, то они не смогли повлиять в значительной мере на техническую эффективность предприятий в 2014 г. В связи с тем что основными нашими партнерами являются Китай, Ирак, Индия и Вьетнам и Алжир, а не страны ЕС, США и Канада.

\section{Список литературы}

1. Ампилогов А.И. Оценка рисков банкротства предприятий-производителей нефтехимического оборудования. М.: Нац. исслед. ун-т «Высшая школа экономики». Сборник лучших выпускных работ - 2011. С. 5-29.

2. Овчинникова Т.А. Исследование конкурентоспособности предприятия на основании DEA-метода // Практический маркетинг. 2009. № 4 (146). С. 20-26.

3. Федорова Е. А., Коркмазова Б.К., Муратов М.А. Оценка эффективности компаний с прямыми иностранными инвестициями: отраслевые особенности в РФ // Пространственная экономика. 2015. № 2. С.47-63.

4. Banker, R.D., Charnes, A., and Cooper, W.W. 1984), "Some models for estimating technical and scale inefficiencies in Data Envelopment Analysis", Management Science, vol. 30, no. 9, pp. 1078-1092.

5. Bray, S., Caggiani, L., and Ottomanelli, M. 2015) "Measuring transport systems efficiency under uncertainty by fuzzy sets theory based Data Envelopment Analysis: theoretical and practical comparison with traditional DEA model", Transportation Research Procedia, no.

1. Военное обозрение. URL: http://topwar.ru/56073-rynok-prodazh-rossiyskogo-oruzhiya-rasshiryaetsya.html. 
5, pp. 186-200,

6. Ghali, S., and Rezgui, S. (2011), "FDI Contribution to Technical Efficiency in The Tunisian Manufacturing Sector”, International Economic Journal, vol. 25, no. 2, pp. 319-339.

7. Ohsato, S., and Takahashi, M. (2015), "Management Efficiency in Japanese Regional Banks: A Network DEA", Procedia - Social and Behavioral Sciences, no. 172, pp. 511-518.

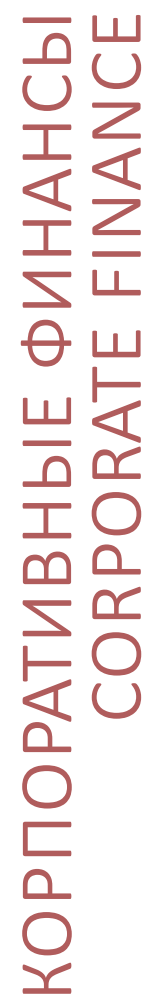


Elena A. Fedorova, Doctor of economic sciences, professor, Department of Financial Management, Financial University under the Government of the Russian Federation

\author{
Anastasiya A. Tkachenko, \\ Department of Financial Management, \\ Financial University under the Government of the Russian Federation \\ Fedor Yu. Fedorov, \\ Department of Applied Mathematics, \\ Financial University under the Government of the Russian Federation
}

Eugene S. Mazalov, Department of Corporate Finance, Financial University under the Government of the Russian Federation

\begin{abstract}
In this study, estimated operating (profitability) and technical efficiency of enterprises of the militaryindustrial complex. The empirical base includes financial and economic indicators 1425 of defense enterprises, research method is a nonparametric method DEA (Data Envelopment analysis). Based on the conducted analysis revealed: 1) it is impossible to evaluate the performance of the MIC based only on technical efficiency. An entity may have low profitability, but due to production specifics, to work more efficiently. 2) enterprises with a high share of state participation (85-100\%) work more efficiently in connection with the modernization of basic production assets and increasing contract base by government programs. 3) Enterprises with a contractual base of over 500 million rubles, have a higher margin (5.1 per cent) than enterprises with a contractual base of less than 500 million rubles (-104\%). 4) sanctions imposed by Western countries against Russian defense enterprises, are unable to significantly affect technical efficiency of enterprises in 2014.
\end{abstract}

Keywords: defense companies, technical efficiency, operational efficiency, sanctions.

JEL

\title{
References
}

1. Ampilogov A. I. Risk Assessment bankruptcy manufacturing petrochemical equipment // Nat. Issled. Univ «Higher School of Economics» Collection of the best final works - 2011. P. 5-29.

2. Ovchinnikov T. A. Study of competitiveness of the enterprise based on DEA-technique // Practical marketing. 2009. № 4 (146). P. 20-26.

3. Fedorova E. A., Korkmazova B.K., Muratov M.A. Evaluation of companies with foreign direct investment: industry especially in the Russian Federation // Spatial Economics. 2015. № 2. P.47-63.

4. Banker R.D., Charnes A., Cooper W.W. Some models for estimating technical and scale inefficiencies in Data Envelopment Analysis // Management Science. 1984. № 30 (9). P. 1078-1092.

5. Bray S., Caggiani L., Ottomanelli M. Measuring transport systems efficiency under uncertainty by fuzzy sets theory based Data Envelopment Analysis: theoretical and practical comparison with traditional DEA model // Transportation Research Procedia. 2015. № 5. P. 186 $-200$

6. Ghali S., Rezgui S. FDI Contribution to Technical Efficiency in The Tunisian Manufacturing Sector // International Economic Journal. 2011. № 25. Issue 2. P. 319-339

7. Ohsato S., Takahashi M. Management Efficiency in Japanese Regional Banks: A Network DEA // Procedia - Social and Behavioral Sciences. 2015. № 172. P. 511 - 518. 